Article

\title{
A Joint Control Model Based on Emission Rights Futures Trading for Regional Air Pollution That Accounts for the Impacts on Employment
}

\author{
Shijie Wang ${ }^{1}$, Laijun Zhao ${ }^{2,3, *(\mathbb{D})}$, Yong Yang ${ }^{4}$, Chenchen Wang ${ }^{1}$, Jian Xue ${ }^{1, *}$, Xin Bo ${ }^{5}$, \\ Deqiang $\mathrm{Li}^{1}$ and Dengguo Liu ${ }^{6,7}$ \\ 1 School of Economics and Management, Shaanxi University of Science and Technology, Xi'an 710021, China; \\ Mobey2018@163.com (S.W.); wangchenchen_sust@163.com (C.W.); 1dqhb@126.com (D.L.) \\ 2 Sino-US Global Logistics Institute, Shanghai Jiao Tong University,1954 Huashan Rd., Shanghai 200030, China \\ 3 Antai College of Economics and Management, Shanghai Jiao Tong University, 1954 Huashan Rd., \\ Shanghai 200030, China \\ 4 School of Arts and Sciences, Shaanxi University of Science \& Technology, \\ University Park of Weiyang District, Xi'an 710021, China; yangyong@sust.edu.cn \\ 5 Appraisal Center for Environment and Engineering, Ministry of Environmental Protection, Beijing 100012, \\ China; boxinet@gmail.com \\ 6 School of Automotive Studies, Tongji University, Shanghai 201804, China; ldg@sheemc.cn \\ 7 Shanghai Environment Monitoring Center, Shanghai 200235, China \\ * Correspondence: ljzhao70@sjtu.edu.cn (L.Z.); xuejian2004@163.com (J.X.); \\ Tel.: +86-1356-446-6215 (L.Z.); +86-1513-009-1180 (J.X.)
}

Received: 10 September 2019; Accepted: 15 October 2019; Published: 23 October 2019

check for updates

\begin{abstract}
To reduce air pollutant control costs and solve the problem of decreased employment caused by air pollution control, we established a double-objective optimization Joint Control Model (JCM) based on emission rights futures trading. The JCM calculates the spot price of emission rights, classifies regions in the trading market for emission rights into buyers and sellers, and calculates the optimal cooperative pollution abatement quantity. Compared with a non-cooperative control mode, the JCM generated benefits of US $\$ 2485.19 \times 10^{6}$. We then used a Game Quadratic Programming (GQP) method to distribute the benefits, and applied the JCM to a case study of the abatement of sulfur dioxide in China's Shanxi, Henan, and Shaanxi provinces. We found that: (i) Compared with a JCM that does not account for employment, employment under the JCM increased by $3.20 \times 10^{3}$ people, and the pollution control cost decreased by US $\$ 11.20 \times 10^{6}$ under the JCM that considered employment. The effect of the latter model is better than that of the former. (ii) Employment under the JCM increased by $18.80 \times 10^{4}$ people compared with that under a territorial control mode, reducing the cost by US $\$ 99.73 \times 10^{6}$. The JCM is helpful for all participating regions to balance environmental and livelihood issues in the process of air pollution control to achieve sustainable development.
\end{abstract}

Keywords: joint control; employment; pollution control cost; emission rights futures; Game Quadratic Programming method

\section{Introduction}

With rapid economic development, regional air pollution, especially in developing countries, has become an increasingly serious global issue. China is one of the countries hit hardest by air pollution in recent years [1]. Air quality in most areas of China, particularly in Beijing, Tianjin, Hebei, the Yangtze River Delta region, the Pearl River Delta region, and the Fen-Wei Plain has been declining since 2011 [2]. Taking the Fen-Wei Plain as an example, complex pollution characterized by a combination of fine 
particulate matter and haze is created in this area, and the average concentration of particles smaller than $2.5 \mu \mathrm{m}\left(\mathrm{PM}_{2.5}\right)$ reached $68 \mu \mathrm{g} \mathrm{m}-3$ in 2018 , seriously affecting the production and health of local residents [3]. Faced with the serious problem of atmospheric pollution, the Chinese government has implemented many laws and policies, one of which is the Action Plan for the Prevention and Control of Atmospheric Pollution. Although the air quality has greatly improved, local governments, which have been required to quickly complete the tasks to control air pollution assigned by the state, have implemented a series of environmental regulation measures, such as closing and relocating polluting enterprises, which could cause a decline in employment [4]. A recent study [5] found that the average employment of pollution-intensive Chinese industries was much higher than that of less-polluting industries from 2007 to 2017. Taking China's Hunan Province as an example, the government-assigned pollution control task was achieved by closing more than 800 enterprises that created serious pollution and transferring them elsewhere in 2017. Although the local environment has improved, employment in Hunan Province decreased by $0.061 \%$, which amounted to $23.29 \times 10^{3}$ people [5]. Therefore, to control air pollution, managers must simultaneously reduce the cost of control, while minimizing the effects on employment.

Various countries take different measures to control air pollution; they include direct control, environment protection tax [6,7], emission trading [8-10], and environmental protection technologies such as recycling and reuse [11,12]. Of these options, air pollution control based on emission rights trading has attracted more attention [13,14]. Dales [15] first proposed the concept of emission trading for pollution, property, and prices. Since then, researchers have shown that the implementation of a carbon emission trading mechanism can achieve significant emission reductions [8]. Moreover, Lin and Jia [16] found that establishing and subsequently improving the emission trading mechanism is an important way to cope with environmental change. Practical experience has shown that emission trading can effectively alleviate environmental pollution $[9,10,14]$. In addition, the theory of financial futures has also been widely used in pollution control [17]. Chicago's Climate Futures Exchange started trading in $\mathrm{SO}_{2}$ futures in 2003. In 2005, the European Climate Exchange also began to test emission rights futures and options for major atmospheric pollutants. The experience of these exchanges suggests that futures or options and other financial instruments for emissions trading can improve air pollution control.

The rest of the paper is structured as follows. Section 2 provides a literature review. Section 3 develops a double-objective optimization model to minimize the pollutant abatement cost and maximize employment based on futures trading. In addition, we use a game quadratic programming (GQP) method to distribute the benefits of joint control. Section 4 provides a Chinese case study on how our model could function in $\mathrm{SO}_{2}$ abatement. Section 5 discussion these results, and Section 6 summarizes the research conclusions.

\section{Literature Review}

In order to reduce the cost of air pollution control, many researchers have analyzed its influencing factors, and put forward methods to reduce the cost [11-13,17,18]. For example, Marina and Andreas [18] studied the European Union Emissions Trading Scheme (ETC) policy of European Aviation, and found that the implementation of emission trading is an effective means to control air pollution, and can reduce the control cost. Lee and Wang [19] argued that emission rights trading should be used to reduce the cost of air pollutant control. In addition to the cost of pollution control, some researchers have also accounted for air quality indexes, adverse health effects, and other related factors $[2,20,21]$. Among them, Xie et al. [2] accounted for both health effects and control cost when studying the effect of air pollution control.

However, no studies have combined pollution control costs with the effects on employment. In fact, especially in developing countries such as China, strict air pollution control has forced many polluting enterprises to relocate or close down, which could lead to a decline in employment in a period of time after the implementation of the policy [22-25]. For example, Gray et al. [25] took the 
American paper industry as an example, and found that strict air pollution control policies led to a decline in employment. Ash and Boyce [26] studied the impact of strict industrial pollutant removal methods on local employment. They found that strict industrial pollutant control decreased local employment. Therefore, the impact of air pollution control on employment should be taken into account to ensure that effective air pollution control measures do not harm the livelihood of citizens affected by these measures.

Experience in developed countries has shown that air pollution will naturally cross borders, and this suggests that cooperation between regions is essential. However, the current air pollution control methods in most developing countries, such as China, is still based on the Territorial Control Mode (TCM) [2]. That is, each region carries out air pollution control in its own jurisdiction, and independently attempts to achieve the targets set for the region to meet national air quality standards. However, the atmospheric environment is fluid and not constrained by such artificial boundaries. Although the TCM facilitates environmental management in a given region, it ignores the natural attributes of the atmospheric environment and fails to protect its integrity $[27,28]$. In addition, under the TCM, it is difficult to take advantage of lower pollution control costs in some regions to achieve the most effective and least expensive regional pollution control [29]. Therefore, to effectively control cross-regional air pollution, it is necessary for regions to cooperate rather than act independently.

Because countries have been exploring effective measures to control cross-regional air pollution, scholars have proposed various methods. Dales [15] first proposed the concept of emission trading based on Coase Theorem. After more than 30 years of development, air pollution control methods based on emission rights trading are now being widely used. For example, Zhou et al. [30] found that the implementation of emission trading, especially carbon emission trading, can effectively reduce carbon dioxide emission and improve environmental quality. Other studies have proposed measures such as air pollution charges [6], green credits [31], and environmental protection tax [7]. However, most research has not considered a combination of emission rights and futures, options, or other financial instruments. In addition, futures and options can also be used to hedge against trading risk [32,33], and assist in price discovery [34]. Therefore, trading in emission rights futures and options is a promising form of market mechanism that can support the administrative means to strengthen the effect of joint control. We therefore adopted futures trading for emission rights to test the ability of this approach to support the goal of regional joint control.

In summary, the innovations of this paper are: (i) An air pollution control model is built that accounts for the employment in the context of regional joint control; and (ii) we proposed a model for emission rights futures trading and examined its effect on pollution control cost and employment.

\section{Materials and Methods}

The JCM includes three sections. In Section 3.2, we develop the employment function and pollutant abatement cost function. In Section 3.3, we develop a joint control model based on emission rights futures trading that accounts for employment. In Section 3.4, we develop a method to distribute the benefits of joint control using the GQP method. Figure 1 shows the modeling framework. 


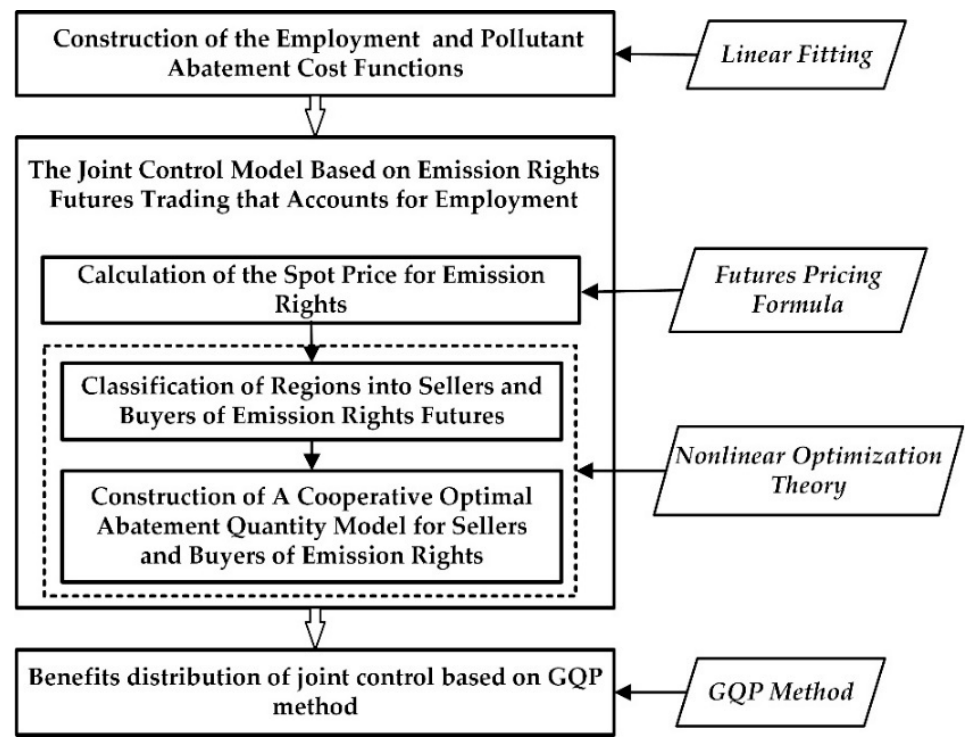

Figure 1. Modeling framework for future-based joint control of regional air pollution. GQP, Game Quadratic Programming.

\subsection{Variables and Parameters}

The variables and main parameters are shown in Table 1.

Table 1. Variables and main parameters.

\begin{tabular}{ccc}
\hline Variable & Definition ( $i$ Represents a Certain Region) & Units (Year ${ }^{-1}$ ) \\
\hline$r_{i}$ & Abatement quantity of an atmospheric pollutant & $10^{4} \mathrm{t}$ \\
\hline Parameters & & \\
\hline$p_{I i}$ & Industrial emissions of an atmospheric pollutant & $10^{4} \mathrm{t}$ \\
$p_{T i}$ & Total emissions of an atmospheric pollutant & $10^{4} \mathrm{t}$ \\
$r c_{i}$ & Abatement cost of an atmospheric pollutant & $\mathrm{US} \$$ \\
$t c_{i}$ & Total cost of an atmospheric pollutant control & $\mathrm{US} \$$ \\
$q_{e i}$ & Emission quota of an atmospheric pollutant & $10^{4} \mathrm{t}$ \\
$q_{r i}$ & Abatement quota of an atmospheric pollutant $\left(q_{r i}=p_{T i}-q_{e i}\right)$ & $10^{4} \mathrm{t}$ \\
$L_{i}$ & Labor input that equals employment & $10^{4}$ people \\
$A_{i}$ & The technology level, which we defined as the number of & piece \\
$K_{i}$ & authorized domestic patents & $\mathrm{US} \$$ \\
$Y_{i}$ & The net value of fixed assets & $\mathrm{US} \$$ \\
\hline
\end{tabular}

\subsection{Construction of Employment and Pollutant Abatement Cost Functions}

In a traditional input-output model, labor, capital, and technology are three key elements that affect economic growth, when it is possible to ignore destruction of the environment caused by a production process. However, in the modern context, environmental destruction is unacceptable, so investments in environmental protection must be accounted for to measure their impact on economic growth [35]. Xue et al. [36] recommended the use of the Cobb-Douglas production function in such analyses; they chose the $\mathrm{SO}_{2}$ abatement quantity $\left(\mathrm{r}_{\mathrm{i}}\right)$ as a factor of investments in environmental protection (i.e., non-production input factor), and chose labor input $\left(\mathrm{L}_{\mathrm{i}}\right)$, technology level $\left(\mathrm{A}_{\mathrm{i}}\right)$, net value of fixed assets $\left(\mathrm{K}_{\mathrm{i}}\right)$, and GDP $\left(\mathrm{Y}_{\mathrm{i}}\right)$ as production input factors. Therefore, the employment function for area $i$ can be expressed as follows (1):

$$
L_{i}=e^{d_{0}} \times A_{i}^{d_{1}} \times K_{i}^{d_{2}} \times Y_{i}^{d_{3}} \times r_{i}^{d_{4}}
$$


To simplify fitting of the parameters, we take the logarithms of both sides of Equation (1):

$$
\ln L_{i}=d_{0}+d_{1} \ln A_{i}+d_{2} \ln K_{i}+d_{3} \ln Y_{i}+d_{4} \ln r_{i}
$$

According to Shi et al. [37], the pollutant abatement cost function in region $i$ is can be expressed as follows (3):

$$
r c_{i}=\theta_{i} \times\left(g_{i} \times x_{i}\right)^{\omega_{i}}
$$

where $\theta_{i}$ and $\omega_{i}\left(\omega_{i}>1\right)$ are parameters to be estimated for region $i, g_{i}$ and $x_{i}$ are the gross emission quantity and abatement rate for a certain industrial air pollutant, respectively, and the abatement quantity of a certain industrial air pollutant can be obtained as $r_{i}=g_{i} \times x_{i}$. Therefore, the cost function for pollutant abatement in region $i$ is:

$$
r c_{i}=\theta_{i} \times\left(r_{i}\right)^{\omega_{i}}
$$

To simplify fitting of the parameters, we take the logarithms of both sides of equation (4):

$$
\ln r c_{i}=\ln \theta_{i}+\omega_{i} \ln r_{i}
$$

\subsection{The Joint Control Model Based On Emission Rights Futures Trading that Accounts for Employment}

Based on the employment function and the pollutant abatement cost function from Section 3.2, we constructed an emission rights futures trading model for joint control that accounts for employment. The model construction follows three steps: In Step 1, we calculate the spot price of emission rights. In Step 2, we classify the participating regions into sellers and buyers of the emission rights futures. In Step 3, we construct a cooperative optimal abatement quantity model for sellers or buyers of emission rights.

\subsubsection{Calculation of the Spot Price for Emission Rights}

The trading of emission rights futures in different regions leads to cost reduction for air pollution control as well as increase in employment. Moreover, it helps to avoid the risk caused by price fluctuation of emission rights in the future due to the future market functions of avoiding risk [32,33] and price discovery [34]. The futures price of emission rights is the expected equilibrium price formed by people according to the supply and demand of spot emission rights. In order to build the JCM of regional air pollution, we need to discount the futures price into spot price. In this paper, we use the futures pricing formula $F=S \times e^{r \times(T-t)}$, which was first proposed by Cornell and French [38], to describe the relationship between the spot price and the futures price. Therefore, the spot price of emission rights can be calculated as follows:

$$
S=F \times e^{r \times(t-T)}
$$

where $T$ represents the expiration date of contract (year), $S$ represents the spot price of air pollution emission rights, $F$ is the theoretical price of air pollution emission rights futures at the maturity date, and $r$ represents the risk-free annual interest rate.

\subsubsection{Classification of Regions into Sellers and Buyers of Emission Rights Futures}

According to Sections 3.2 and 3.3.1, the total cost of an atmospheric pollutant control $t c_{i}$ includes the pollutant abatement $\operatorname{cost} \theta_{i} \times\left(r_{i}\right)^{\omega i}$ and the emission rights futures transaction $\operatorname{cost}\left(q_{\mathrm{r} i}-r_{i}\right) \times S$. Thus, we constructed an emission rights futures trading model that accounts for employment under a Non-cooperative Control Mode (NCM), as shown in Equations (7) to (9). By solving the model, the optimal pollutant abatement quantity $\hat{r}_{i}$ in different regions under the NCM can be obtained. Thus, 
the trading market for emission rights can be divided based on the value of $\hat{r}_{i}$ with the pollutant abatement quota $q_{r i}$ for region $i$ prescribed by the state:

$$
\begin{aligned}
& \left\{\begin{array}{c}
\max _{r_{i}} L_{i}=\mathrm{e}^{d_{0}} \times A_{i}^{d_{1}} \times K_{i}^{d_{2}} \times Y_{i}^{d_{3}} \times r_{i}^{d_{4}} \\
\min _{r_{i}} t c_{i}=\theta_{i} \times\left(r_{i}\right)^{\omega_{i}}+\left(q_{r i}-r_{i}\right) \times S
\end{array}\right. \\
& \text { s.t. } \\
& p_{T i}-r_{i} \leq \lambda \times q_{e i} \\
& \alpha_{i} \times p_{I i} \leq r_{i} \leq \beta_{i} \times p_{I i} \\
& i=1,2, \cdots, n
\end{aligned}
$$

Equation (7) represents the objectives of maximizing employment and minimizing the total pollution control cost, respectively. Equations (8) to (9) are the constraints of the double-objective optimization model. Equation (8) means that the total pollutant emission minus the total pollutant abatement quantity in a certain region shall not exceed the environmental capacity of the region (i.e. the maximum permissive emission of pollutants), which equals the emission quota for region $i$ prescribed by the state multiplied by a coefficient lambda. Equation (9) means that the capacity of region $i$ to control pollutants has a given range. When a regional exhaust gas treatment facility works at full load, additional pollutants cannot be removed completely. At the same time, the abatement quantity of pollutants cannot be zero. Therefore, the capacity of each region to deal with pollutants has a maximum $\left(\beta_{\mathrm{i}} \times p_{I i}\right)$ value and a minimum $\left(\alpha_{i} \times p_{I i}\right)$ value [17].

Under the NCM, the optimal pollutant abatement quantity $\hat{r}_{i}$ in each region is compared with the pollutant abatement quota $q_{r i}$ prescribed by the state for region $i$. If $\hat{r}_{i}>q_{r i}$, region $i$ is the seller of the emission right (i.e., region $i$ helps other areas to reduce their pollutants) and the sale amount is $\hat{r}_{i}-q_{r i}$; if $\hat{r}_{j}<q_{r j}$, region $j$ is the buyer of the emission rights (i.e., other regions help region $j$ to compensate for the lack of emission reductions) and the buy amount is $q_{r j}-\hat{r}_{j}$. In this context, we can identify $n$ seller areas that form a group $G_{1}$ and $m$ buyer areas that form a group $G_{2}$.

According to the above rules, if the futures price is too high or too low, all traders are sellers or buyers of emission rights, and cannot form a trading market. In that situation, each region can only independently complete its pollutant abatement quota prescribed by the state. If a futures price makes the seller's sale amount equal to the buyer's purchase amount, the abatement quantity $\hat{r}_{i}$ for region $i$ under the NCM is its optimal abatement quantity, that is, $r_{i}^{*}=\hat{r}_{i}$. The abatement quantity $\hat{r}_{j}$ for region $j$ under the NCM is then its optimal abatement quantity, that is, $r_{j}{ }^{*}=\hat{r}_{j}$. At this time, the abatement quantity of each side has reached its optimal value, and there is no need for cooperation. Therefore, two types of cooperative markets can be formed given a moderate futures price:

Type (i): the seller sells more than the buyer buys.

Type (ii): the seller sells less than the buyer buys.

3.3.3. Construction of a Cooperative Optimal Abatement Quantity Model for Sellers and Buyers of Emission Rights

\section{Optimal Abatement Quantity Model with Seller Cooperation}

In this case, the sellers sell more than the buyers buy; thus, the optimal abatement quantity for buyer's region $j$ is equal to that of the buyer's region under the NCM; that is $r_{j}{ }^{*}=\hat{r}_{j}$. At this point, the buyer's purchase amount is determined; that is, $q_{r i}-\hat{r}_{j}$. Therefore, through cooperation, $n$ seller regions reach overall optimum and get their respective pollutant abatement quantity. 
The regional JCM for sellers is as follows:

$$
\begin{aligned}
& \left\{\begin{array}{c}
\max _{r_{i}} \sum_{i \in G_{1}} L_{i}=\mathrm{e}^{d_{0}} \times A_{i}^{d_{1}} \times K_{i}^{d_{2}} \times Y_{i}^{d_{3}} \times r_{i}^{d_{4}} \\
\min _{r_{i}} \sum_{i \in G_{1}} t c_{i}=\theta_{i} \times\left(r_{i}\right)^{\omega_{i}}+\left(q_{r i}-r_{i}\right) \times S
\end{array}\right. \\
& \text { s.t. } \\
& p_{T i}-r_{i} \leq \lambda \times q_{e i} \\
& \alpha_{i} \times p_{I i} \leq r_{i} \leq \beta_{i} \times p_{I i} \\
& q_{r i} \leq r_{i} \\
& \sum_{i \in G_{1}} r_{i}=\sum_{i \in G_{1}} q_{r i}+\sum_{j \in G_{2}} q_{r j}-\hat{r}_{j} \\
& i=1,2, \cdots, n
\end{aligned}
$$

Equation (10) indicates that the total cost of pollution control in the seller regions that are participating in joint control is minimized and employment is maximized, respectively. Equations (11) and (12) have the same meaning as Equations (8) and (9), respectively. Equation (13) indicates that the abatement quantity in the seller's area must be greater than the pollutant abatement quota prescribed by the state. Equation (14) indicates that the total pollutant abatement quantity in the seller's area equals the abatement quantity of the pollutants that is purchased plus the pollutant abatement quota prescribed by the state.

This model provides the optimal abatement quantity $r_{i}^{*}$ in each seller region, which ensures minimum total control cost and maximum employment in the seller's region.

Remarkably, in a market where each seller has the same trading power for emission rights, sellers will first complete the pollutant abatement quota prescribed by the state under the NCCM, then determine the emission indicators that it can sell in the trading market. Therefore, the calculation equation for each seller's pollutant abatement quantity is:

$$
r_{i}=q_{r i}+\left(\hat{r}_{i}-q_{r i}\right) \times \sum_{j \in G_{2}}\left(q_{r j}-\hat{r}_{j}\right) / \sum_{i \in G_{1}}\left(\hat{r}_{i}-q_{r i}\right)
$$

Optimal Abatement Quantity with Buyer Cooperation

In this case, the sellers sell less than the buyers buy; thus, the optimal abatement quantity of seller region $i$ is equal to that of the seller's area under the NCM; that is $r_{i}^{*}=\hat{r}_{i}$. At this point, the selling quantity is determined. Therefore, through cooperation, $m$ buyer regions reach the overall optimum and get their respective pollutant abatement quantity.

The regional JCM for buyers is as follows:

$$
\begin{aligned}
& \left\{\begin{array}{l}
\max _{r_{j}} \sum_{j \in G_{2}} L_{j}=\mathrm{e}^{d_{0}} \times A_{j}^{d_{1}} \times K_{j}^{d_{2}} \times Y_{j}^{d_{3}} \times r_{j}^{d_{4}} \\
\min _{r_{j}} \sum_{j \in G_{2}} t c_{i}=\theta_{j} \times\left(r_{j}\right)^{\omega_{j}}+\left(q_{r j}-r_{j}\right) \times S
\end{array}\right. \\
& \text { s.t. } \\
& p_{T j}-r_{j} \leq \lambda \times q_{e j} \\
& \alpha_{j} \times p_{I j} \leq r_{j} \leq \beta_{j} \times p_{I j} \\
& r_{j} \leq q_{r j}
\end{aligned}
$$




$$
\begin{gathered}
\sum_{i \in G_{1}} r_{i}=\sum_{i \in G_{1}} q_{r i}+\sum_{j \in G_{2}} q_{r j}-\hat{r}_{j} \\
j=1,2, \cdots, m
\end{gathered}
$$

In contrast with the seller's JCM, Equation (19) indicates that the abatement quantity for the buyer's region should be less than the abatement quota prescribed by the state, but the other equations are the same as in the seller's regional JCM. Through this model, the optimal abatement quantity under the buyer's JCM can be obtained.

\subsection{Distribution of the Benefits from Joint Control Based on the Game Quadratic Programming (GQP) Method}

The increase of employment can be treated as a benefit from investments in atmospheric pollutant control. The sum of the product of the increased employment in the region under the JCM and the per capita labor output $\left(g_{i}\right)$ in the region can be defined as the total income $\left(\sum_{i=1}^{n} I_{i}\right)$ from the increase in employment:

$$
\sum_{i=1}^{n} I_{i}=\sum_{i=1}^{n}\left[g_{i} \times\left(L_{i c}-L_{i s}\right)\right]
$$

where $L_{i c}$ represents the employment under the JCM, $L_{i s}$ represents the employment under the NCM, and the per capita labor output in a given year for region $i$ is the ratio of GDP to employment in that year.

The total $\operatorname{cost}\left(\sum_{i=1}^{n} T C_{i}\right)$ saved by air pollution control in all regions equals the total cost of pollutant abatement $\left(C_{i s}\right)$ under NCM minus the corresponding cost $\left(C_{i c}\right)$ under JCM:

$$
\sum_{i=1}^{n} T C_{i}=\sum_{i=1}^{n} C_{i s}-\sum_{i=1}^{n} C_{i c}
$$

Therefore, compared with the NCM, the total benefit $\left(\sum_{i=1}^{n} T B_{i}\right)$ achieved under the JCM can be expressed as the sum of the total income $\left(\sum_{i=1}^{n} I_{i}\right)$ achieved by the increase of employment under the JCM and the total $\operatorname{cost}\left(\sum_{i=1}^{n} T C_{i}\right)$ saved by air pollution control:

$$
\sum_{i=1}^{n} T B_{i}=\sum_{i=1}^{n} I_{i}+\sum_{i=1}^{n} T C_{i}
$$

We define the total benefit of joint control for $n$ regions as $C(N)$ :

$$
C(N)=\sum_{i=1}^{n} T B_{i}=\sum_{i=1}^{n} I_{i}+\sum_{i=1}^{n} T C_{i} \quad \forall i \in N
$$

Joint control of air pollution in different regions will inevitably involve benefit distribution. Thus, in order to reach the overall and individual optimum of cooperative alliance simultaneously, the fair distribution of cooperative benefits becomes the key to regional air pollution joint control. At present, the main approaches for the distribution of these benefits are the Shapley value method [39], the Nucleolus method [39], the GQP method [40], and the Minimum Cost-Remaining Saving method [41]. The GQP method is often used to solve the problem of benefit-sharing in a multi-agent cooperative game. This method combines the advantages of Shapley value method, the Nucleolus method, and the Minimum Cost-Remaining Saving method, which satisfies the rationality of the benefits acquired 
by each member [40]. Therefore, we chose the GQP method to distribute the benefits of regional cooperation in air pollution control.

The main idea behind the GQP method is to first determine the maximum benefit allocated to each region, which represents the ideal allocation, and then construct a distance function to quantify how far each solution is from the ideal benefit distribution. The specific model is shown in Equations (25) to (28).

$$
\begin{gathered}
\min _{x_{i}} Z=\sum_{i \in N}\left(x_{i}-v_{i}\right)^{2} \\
\sum_{i \in N} x_{i}=C(N) \quad \forall i \in N \\
\sum_{i \in S} x_{i} \geq C(S) \quad \forall S \subset N \\
x_{i} \geq c_{i} \quad \forall i \in N
\end{gathered}
$$

where $C(N)$ is the total benefit obtained by all regions under the JCM and $C(S)$ is the cooperative benefits of alliance $S$ formed in different regions. Equation (25) indicates that the goal is to minimize the distance between the actual and ideal allocations of benefits among the regions participating in the cooperation, in which $x_{i}$ represents the income obtained by region $i$ under the JCM, and $v_{i}$ represents the ideal allocation obtained by region $i$; that is, $v_{i}=C(S)-C(S \backslash\{i\})$. $C(S \backslash\{i\})$ represents the benefits for other regions when region $i$ does not participate in cooperation. Equation (26) ensures that the sum of the benefits obtained by all regions participating in joint control equals the total benefit obtained by all regions under the JCM. Equation (27) ensures that the sum of the benefit obtained by each member in the alliance $S$ should be greater than the total benefits of the alliance $S$. Equation (28) ensures that the benefits obtained by each region under the JCM should be greater than those of each region under the NCM.

\section{Case Study}

The model proposed in this paper is suitable not only for joint control of air pollution in different regions, but also for joint control in different industries, and other fields. Here, we choose the Fen-Wei Plain as a case study. The Fen-Wei Plain is the name of the combination of the Fenhe Plain and the Weihe Plain in China's Yellow River Basin. The plain includes 11 large cities in Shanxi, Henan, and Shaanxi provinces. In recent years, air pollution in Fen-Wei Plain has become more serious. Especially in 2017, the average annual $\mathrm{PM}_{2.5}$ concentration reached $68 \mathrm{ug} \cdot \mathrm{m}^{-3}$, making this region one of the most polluted areas in China [42]. Because data for all 11 cities were difficult to obtain, we chose a pollutant $\left(\mathrm{SO}_{2}\right)$ for which data was available for all three provinces in 2017, then used this data to perform a case study of the JCM based on futures prices. Figure 2 show the locations of the three provinces and their air quality on 25 January 2017.

The case study includes five sections. In Section 4.1, we use statistical data to fit the employment function and $\mathrm{SO}_{2}$ abatement cost function of Shanxi, Henan, and Shaanxi provinces. In Section 4.2, we calculate spot price of $\mathrm{SO}_{2}$ emission rights with futures pricing formula. In Section 4.3, we establish a double-objective optimization model for three provinces under the NCM using the employment function and $\mathrm{SO}_{2}$ abatement cost function, then classify regions into sellers and buyers of emission rights futures. In Section 4.4, the $\mathrm{SO}_{2}$ abatement quantity of Henan and Shaanxi provinces is calculated under the JCM. In Section 4.5, we apply the GQP method to distribute the cooperation benefits between Henan and Shaanxi provinces. 


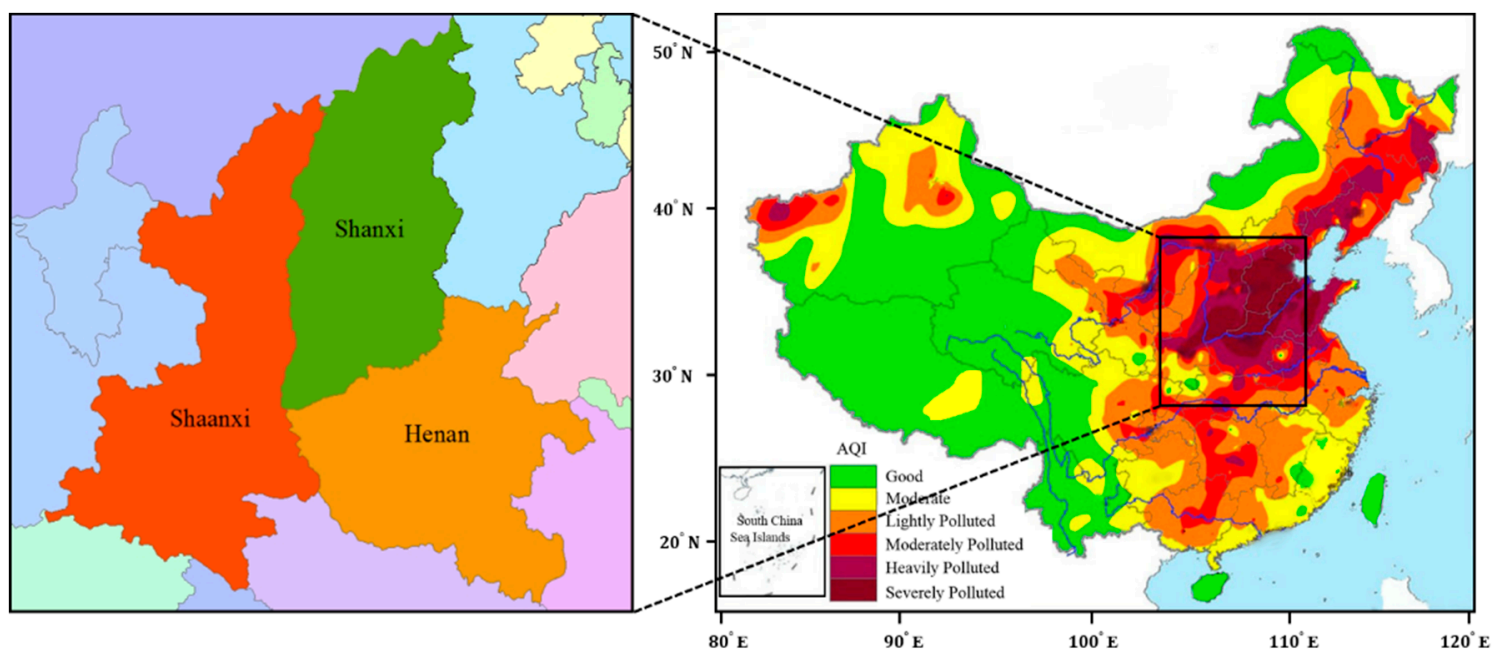

Figure 2. Location of Shanxi, Henan, and Shaanxi provinces and air pollution distribution based on the air quality index (AQI) on 25 January 2017.

\subsection{Case Study of the Joint Control Model (JCM) for Regional Air Pollution Control}

We used version 24 of the SPSS software to fit all the equations.

\subsubsection{Employment Function}

We fit Equation (2) using year-end employment data [43], technology level data [44], net fixed asset values data [45], and GDP data [46] in the study region from 2000 to 2017, totaling 270 data. The results are shown in Table 2.

Table 2. Parameter estimation results of employment function in the study region.

\begin{tabular}{|c|c|c|c|c|c|c|c|c|}
\hline \multirow{2}{*}{ Province } & \multirow{2}{*}{$\begin{array}{c}\text { Employment Function } \\
\text { Units }\left(L_{i}: 10^{4} \text { People; } r_{i}: 10^{4} t\right)\end{array}$} & \multicolumn{7}{|c|}{ Parameter Estimation Results } \\
\hline & & $d_{0}$ & $d_{1}$ & $d_{2}$ & $d_{3}$ & $d_{4}$ & $R^{2}$ & $F$-Test \\
\hline Shanxi & $L_{1}=2384.49 r_{1}^{-0.038}$ & 5.907 & 0.051 & 0.103 & 0.044 & -0.038 & 0.994 & $278.149^{* * *}$ \\
\hline Henan & $L_{2}=7233.97 r_{2}^{-0.033}$ & 7.865 & 0.014 & 0.129 & -0.030 & -0.033 & 0.997 & $477.385^{* * *}$ \\
\hline Shaanxi & $L_{3}=1806.82 r_{3}^{0.027}$ & 7.634 & 0.000 & 0.008 & -0.021 & 0.027 & 0.949 & $37.329^{* * *}$ \\
\hline
\end{tabular}

\subsection{2. $\mathrm{SO}_{2}$ Abatement Cost Function}

We used $\mathrm{SO}_{2}$ abatement quantity data and abatement cost data from 2000 to 2017 [47] to fit equation (5), totaling 108 data. The results are as follows (Table 3).

Table 3. Parameter estimation results for the $\mathrm{SO}_{2}$ abatement cost functions in the study region.

\begin{tabular}{|c|c|c|c|c|c|}
\hline \multirow{2}{*}{ Province } & \multirow{2}{*}{$\begin{array}{l}\mathrm{SO}_{2} \text { Abatement Cost Function } \\
\text { Units }\left(r c_{i}: \text { US } \$ ; r_{i}: 10^{4} \mathrm{t}\right)\end{array}$} & \multicolumn{4}{|c|}{ Parameter Estimation Results } \\
\hline & & $\ln \theta_{i}$ & $\omega_{i}$ & $R^{2}$ & $F$-Test \\
\hline Shanxi & $r c_{1}=121.75 r_{1}^{1.418}$ & 4.802 & 1.418 & 0.934 & $199.127^{* * *}$ \\
\hline Henan & $r c_{2}=39.33 r_{2}^{1.613}$ & 3.672 & 1.613 & 0.971 & $462.910^{* * *}$ \\
\hline Shaanxi & $r c_{3}=176.80 r_{3}{ }^{1.373}$ & 5.175 & 1.373 & 0.981 & $712.016^{* * *}$ \\
\hline
\end{tabular}

\subsection{Calculation for Spot Price of Emission Rights}

We assumed that China has a sound futures market for pollutant emission rights, and limited the trading to China. We also assumed that the market was frictionless, and had the same and unchanged lending interest rate. Assuming that the price of $\mathrm{SO}_{2}$ futures price we observed on the futures exchange 
in January 2020 was US $\$ 1922.46 \mathrm{t}^{-1}$, the spot price for emission rights calculated using Equation (6) was $S=\mathrm{US} \$ 1770.22 \mathrm{t}^{-1}$, based on a three-year deposit interest rate of $r=2.75 \%$ in January 2017, and a holding period from $t=0$ years to $T=3$ years.

\subsection{Classification of Regions into Sellers and Buyers of Emission Rights}

The data of total $\mathrm{SO}_{2}$ production $\left(p_{\mathrm{T} i}\right)$ in 2017, total industrial $\mathrm{SO}_{2}$ production $\left(p_{\mathrm{Ii}}\right)$ in 2017, and the $\mathrm{SO}_{2}$ emission quota $\left(q_{\mathrm{e} i}\right)$ in 2017 for the three provinces are as follows $[47,48]$.

We assigned coefficient values of $\alpha_{i}=0.4, \beta_{i}=0.9$, and $\lambda_{i}=1.3$ [49]. On this basis, the optimal $\mathrm{SO}_{2}$ abatement quantity under the NCM for the three provinces in the study region was calculated as follows:

$$
\begin{aligned}
& \text { Shanxi : } \quad\left\{\begin{array}{l}
\max _{r_{1}} L_{1}=2384.49 \times r_{1}^{-0.038} \\
\min _{r_{1}} c_{1}=121.75 \times r_{1}^{1.418}+1770.22 \times\left(288.20-r_{1}\right)
\end{array}\right. \\
& \text { s.t. } \\
& 342.19 \geq r_{1} \geq 257.27 \\
& \text { Henan : } \quad\left\{\begin{array}{l}
\max _{r_{2}} L_{2}=7233.97 \times r_{2}^{-0.033} \\
\min _{r_{2}} t c_{2}=39.33 \times r_{2}^{1.613}+1770.22 \times\left(178.51-r_{2}\right)
\end{array}\right. \\
& \text { s.t. } \\
& 242.29 \geq r_{2} \geq 148.02 \\
& \text { Shaanxi : } \quad\left\{\begin{array}{l}
\max _{r_{3}} L_{3}=1806.82 \times r_{3}^{0.027} \\
\min _{r_{3}} t c_{3}=176.80 \times r_{3}^{1.373}+1770.22 \times\left(111.53-r_{3}\right)
\end{array}\right. \\
& \text { s.t. } \\
& 150.85 \geq r_{3} \geq 91.06
\end{aligned}
$$

We then solved the double-objective optimization problem:

$$
\min _{r_{i}} f=\frac{t c_{i}}{L_{i}}
$$

Using this equation, the optimal abatement quantity of each region under the NCM can be calculated as follows: $\hat{r}_{1}=257.27 \times 10^{4} \mathrm{t}, \hat{r}_{2}=223.19 \times 10^{4} \mathrm{t}$, and $\hat{r}_{3}=150.85 \times 10^{4} \mathrm{t}$.

According to Table 4, the $\mathrm{SO}_{2}$ abatement quotas for the three provinces are $q_{r 1}=288.20 \times 10^{4} \mathrm{t}$, $q_{r 2}=178.51 \times 10^{4} \mathrm{t}$, and $q_{r 3}=111.53 \times 10^{4} \mathrm{t}$. Then $q_{r 1}-\hat{r}_{1}=30.93 \times 10^{4} \mathrm{t}, \hat{r}_{2}-q_{r 2}=44.68 \times 10^{4} \mathrm{t}$, $\hat{r}_{3}-q_{r 3}=39.32 \times 10^{4} \mathrm{t}$, Henan and Shaanxi are sellers of emission rights, and Shanxi is the buyer of the emission rights based on our criteria for the division of buyers and sellers in Section 3.3.

Table 4. $\mathrm{SO}_{2}$ control indicators in the three provinces in 2017.

\begin{tabular}{cccc}
\hline Control Indicators $\left(\right.$ Unit: $\left.\times \mathbf{1 0}^{\mathbf{4}} \mathbf{t}\right)$ & Shanxi & Henan & Shaanxi \\
\hline Total $\mathrm{SO}_{2}$ production $\left(p_{T i}\right)$ & 391.30 & 280.13 & 179.74 \\
Total production of industrial $\mathrm{SO}_{2}\left(p_{I i}\right)$ & 380.21 & 269.21 & 167.62 \\
$\mathrm{SO}_{2}$ emission quota $\left(q_{e i}\right)$ & 103.10 & 101.62 & 68.21 \\
$\mathrm{SO}_{2}$ abatement quota $\left(q_{r i}=p_{T i}-q_{\mathrm{e} i}\right)$ & 288.20 & 178.51 & 111.53 \\
\hline
\end{tabular}

\subsection{Optimal Abatement Model under the Joint Control Model (JCM)}

From the solutions in the previous section and related data, it can be seen that:

$$
\left(\hat{r}_{2}-q_{r 2}\right)+\left(\hat{r}_{3}-q_{r 3}\right)=84.00 \times 10^{4} \mathrm{t}>\left(q_{r 1}-\hat{r}_{1}\right)=30.93 \times 10^{4} \mathrm{t}
$$


That is, the total abatement quantity for the sellers is greater than that of the buyer, so the model is the Type (i) emission trading market we defined in Section 3.3.2. Henan and Shaanxi should cooperate to minimize the cost of pollutant abatement. The total abatement quantity of pollutants is $q_{r 2}+q_{r 3}+\left(q_{r 1}-\hat{r}_{1}\right)=320.97 \times 10^{4} \mathrm{t}$. The JCM for Henan and Shaanxi is as follows:

$$
\left\{\begin{array}{l}
\max _{r_{2}, r_{3}} \sum_{i \in G_{1}} L_{i}=7233.97 \times r_{2}^{-0.033}+1806.82 \times r_{3}^{0.027} \\
\min _{r_{2}, r_{3}} \sum_{i \in G_{1}} t c_{i}=39.33 \times r_{2}^{1.613}+1770.22 \times\left(178.51-r_{2}\right)+176.80 \times r_{3}^{1.373}+1771.22 \times\left(111.53-r_{3}\right)
\end{array}\right.
$$

s.t.

$$
\begin{gathered}
242.29 \geq r_{2} \geq 178.51 \\
150.85 \geq r_{3} \geq 111.53 \\
r_{2}+r_{3}=320.97
\end{gathered}
$$

Solving the double-objective optimization problem:

$$
\min _{r_{i}} k=\frac{\sum_{i \in G_{1}} t c_{i}}{\sum_{i \in G_{1}} L_{i}}
$$

From this equation, it can be concluded that the optimal abatement quantities for Henan and Shaanxi provinces under the JCM are $r_{2}^{*}=180.57 \times 10^{4} \mathrm{t}$ and $r_{3}^{*}=140.40 \times 10^{4} \mathrm{t}$, respectively.

\subsection{Distribution of the Benefits from Joint Control Based on the Game Quadratic Programming (GQP) Method}

To ensure cooperation between Henan and Shaanxi provinces, it is necessary to provide a fair distribution of the benefits of cooperation. To do so, we used Equation (15), and calculated the pollutant abatement quantities at $194.96 \times 10^{4} \mathrm{t}$ for Henan and $126.01 \times 10^{4} \mathrm{t}$ for Shaanxi under the NCM. The income under the JCM is shown in Table 5, in which the per capita labor output $\left(g_{i}\right)$ in 2017 is the ratio of GDP to employment in that year.

Table 5. Income under the joint control model (JCM).

\begin{tabular}{cccc}
\hline Key Indicators & Henan & Shaanxi & Total \\
\hline $\mathrm{SO}_{2}$ Abatement quantity under the $\mathrm{NCM}\left(\times 10^{4} \mathrm{t}\right)$ & 194.96 & 126.01 & 320.97 \\
(1) $\mathrm{SO}_{2}$ control cost under the $\mathrm{NCM}\left(\times 10^{6} \mathrm{US} \$\right)$ & 1651.50 & 1096.80 & 2748.30 \\
(2) Employment under the NCM $\left(\times 10^{4}\right.$ people) & 6078.67 & 2058.86 & 8137.53 \\
\hline $\mathrm{SO}_{2}$ Abatement quantity under the JCM $\left(\times 10^{4} \mathrm{t}\right)$ & 180.57 & 140.40 & 320.97 \\
(3) $\mathrm{SO}_{2}$ control cost under the JCM $\left(\times 10^{6} \mathrm{US} \$\right)$ & 1680.23 & 1058.64 & 2738.87 \\
(4) Employment under the JCM $\left(\times 10^{4}\right.$ people $)$ & 6094.07 & 2064.88 & 8158.95 \\
\hline A Savings in $\mathrm{SO}_{2}$ control cost $($ Benefits $)=(\mathbf{1})-(\mathbf{3})\left(\times 10^{6} \mathrm{US} \$\right)$ & -28.73 & 38.16 & 9.43 \\
B Increase in employment $=\mathbf{( 4 )}-(\mathbf{2})\left(\times 10^{4}\right.$ people) & 15.40 & 6.02 & 21.42 \\
C GDP per capita in $2017\left(\times 10^{4} \mathrm{US} \$\right)$ & 0.99 & 1.58 & \\
D Benefits due to increased employment $=\mathbf{B} \times \mathbf{C}\left(\times 10^{6} \mathrm{US} \$\right)$ & 1524.60 & 951.16 & 2475.76 \\
\hline Benefits due to cooperation $=\mathbf{A}+\mathbf{D}\left(\times 10^{6} \mathrm{US} \$\right)$ & 1495.87 & 989.32 & 2485.19 \\
\hline
\end{tabular}

Table 5 shows that the total benefit for Henan and Shaanxi under the JCM is US\$2485.19 $\times 10^{6}$; that is, the total benefit of alliance formed by Henan and Shaanxi is $C(n)=\mathrm{US} \$ 2485.19 \times 10^{6}$. If we use the numbers 2 and 3 to represent Henan and Shaanxi, respectively, then the maximum income distributed is $v_{2}=$ US $\$ 2485.19 \times 10^{6}$ and the maximum income distributed is $v_{3}=\mathrm{US} \$ 2485.19 \times 10^{6}$. Because there are only two provinces participating in the cooperation, the cooperation income obtained by one province is zero when the other province does not participate in the cooperation. 
Therefore, the JCM benefits distribution model in Henan and Shaanxi is as follows:

$$
\begin{aligned}
\min _{x_{2}, x_{3}}\left[\left(x_{2}-2485.19\right)^{2}+\left(x_{3}-2485.19\right)^{2}\right] \\
\text { s.t. } \\
x_{2}+x_{3}=2485.19 \\
x_{2}>0 \\
x_{3}>0
\end{aligned}
$$

Henan and Shaanxi should receive distribution of US $\$ 1242.595 \times 10^{6}$ by solving the above equation under the JCM.

\section{Discussion}

\subsection{Comparison of the Joint Control Model (JCM) with and without Accounting for Employment}

Under the JCM, the minimum cost of pollution control can only be guaranteed if employment is not considered. The control cost and employment under the JCM without considering employment can be obtained using the cost functions. However, it is essential to maximize employment, so we

\begin{tabular}{|c|c|c|c|c|}
\hline Key Indicators & Shanxi & Henan & Shaanxi & Total \\
\hline $\begin{array}{l}\text { Optimal } \mathrm{SO}_{2} \text { abatement quantity under the JCM without } \\
\text { considering employment }\left(q_{r i}, \times 10^{4} \mathrm{t}\right)\end{array}$ & 262.05 & 178.63 & 137.56 & 578.24 \\
\hline $\begin{array}{c}\text { A SO } \mathrm{SO}_{2} \text { control cost under the JCM without considering } \\
\text { employment }\left(\times 10^{6} \text { US } \$\right)\end{array}$ & 3734.34 & 1684.92 & 1065.48 & 6484.74 \\
\hline $\begin{array}{l}\text { C Employment under the JCM without considering } \\
\text { employment }\left(\times 10^{4} \text { people }\right)\end{array}$ & 1929.73 & 6096.24 & 2063.74 & $10,089.71$ \\
\hline $\begin{array}{l}\text { Optimal } \mathrm{SO}_{2} \text { abatement quantity under the JCM } \\
\text { considering employment }\left(r_{i}^{*}, \times 10^{4} \mathrm{t}\right)\end{array}$ & 257.27 & 180.57 & 140.40 & 578.24 \\
\hline $\begin{array}{c}\text { B SO} ~_{2} \text { control cost under the JCM considering } \\
\text { employment }\left(\times 10^{6} \text { US } \$\right)\end{array}$ & 3734.67 & 1680.23 & 1058.64 & 6473.54 \\
\hline $\begin{array}{l}\text { D Employment under the JCM considering employment } \\
\qquad\left(\times 10^{4} \text { people }\right)\end{array}$ & 1931.08 & 6094.07 & 2064.88 & $10,090.03$ \\
\hline Savings in $\mathrm{SO}_{2}$ control cost (Benefits) $=\mathbf{A}-\mathbf{B}\left(\times 10^{6}\right.$ US\$) & -0.33 & 4.69 & 6.84 & 11.20 \\
\hline Increase in employment $=\mathbf{D}-\mathbf{C}\left(\times 10^{4}\right.$ people $)$ & 1.35 & -2.17 & 1.14 & 0.32 \\
\hline
\end{tabular}
compared the cost and employment levels for models that did and did not account for employment (Table 6).

Table 6. Comparison of pollutant control costs and employment under the joint control model (JCM) with and without considering employment.

Table 6 shows that the $\mathrm{SO}_{2}$ control cost for the study region was US $\$ 6484.74 \times 10^{6}$ under the JCM without considering employment, versus US $\$ 6473.54 \times 10^{6}$ when employment is considered. Thus, considering employment saves US\$11.20 $\times 10^{6}$. Under the JCM without considering employment, the total employment in the study regions is $100.8971 \times 10^{6}$ people, versus $100.9003 \times 10^{6}$ people when employment is considered. Thus, considering employment increases the total employment by $3.20 \times 10^{3}$ people. The cost of $\mathrm{SO}_{2}$ control in Shanxi increased when employment was considered. This may be because coal and other industries that consume large amounts of energy are pillar industries in Shanxi [50]. Employment depends strongly on these industries, which also cause serious pollution in Shanxi. Therefore, the province needs to pay a higher control cost to ensure maximum employment. However, for the whole study region, the total control cost decreased. In addition, under the JCM that considered employment, employment in Henan decreased. The main reason may be that Henan's population is large; thus, strengthening pollution control has negative consequences caused 
by industrial restructuring, which would cause large numbers of people to move to the surrounding areas, resulting in locally decreased employment. Overall, however, employment in the three regions increased, suggesting that it may be necessary for the government to help unemployed workers move from Henan to one of the other regions to fill new jobs created in those other regions.

\subsection{Comparison of Control Effectiveness between the Territorial Control Mode (TCM) and the Joint Control Model (JCM)}

The three provinces must achieve the $\mathrm{SO}_{2}$ abatement quotas prescribed by the state independently under the TCM; however, under the JCM developed in this paper, Shanxi is the buyer of emission rights, and Henan and Shaanxi are the sellers of emission rights. Table 7 summarizes the employment and $\mathrm{SO}_{2}$ control costs for the three regions under the two models.

Table 7. Comparison of pollutant control costs and employment under the territorial control mode (TCM) and the joint control model (JCM).

\begin{tabular}{|c|c|c|c|c|}
\hline Key Indicators & Shanxi & Henan & Shaanxi & Total \\
\hline $\mathrm{SO}_{2}$ abatement quota under the TCM $\left(q_{-r i}, \times 10^{4} \mathrm{t}\right)$ & 288.20 & 178.51 & 111.53 & 578.24 \\
\hline A SO ${ }_{2}$ control cost under the TCM $\left(\times 10^{6}\right.$ US\$) & 3743.82 & 1685.22 & 1144.33 & 6573.37 \\
\hline C Employment under the TCM $\left(\times 10^{4}\right.$ people $)$ & 1922.77 & 6096.38 & 2052.08 & $10,071.23$ \\
\hline Optimal $\mathrm{SO}_{2}$ abatement quantity under the JCM $\left(r_{i}^{*}, \times 10^{4} \mathrm{t}\right)$ & 257.27 & 180.57 & 140.40 & 578.24 \\
\hline B $\mathrm{SO}_{2}$ control cost under the JCM $\left(\times 10^{6}\right.$ US\$) & 3734.77 & 1680.23 & 1058.64 & 6473.64 \\
\hline D Employment under the JCM $\left(\times 10^{4}\right.$ people $)$ & 1931.08 & 6094.07 & 2064.88 & $10,090.03$ \\
\hline Savings in $\mathrm{SO}^{2}$ control cost (Benefits) $=\mathbf{A}-\mathbf{B}\left(\times 10^{6}\right.$ US\$) & 9.05 & 4.99 & 85.69 & 99.73 \\
\hline Increase in employment $=\mathbf{D}-\mathbf{C}\left(\times 10^{4}\right.$ people $)$ & 8.31 & -2.31 & 12.80 & 18.80 \\
\hline
\end{tabular}

Table 7 shows that the cost of $\mathrm{SO}_{2}$ control for the study region was US $\$ 6573.37 \times 10^{6}$ under the TCM, versus US $\$ 6473.64 \times 10^{6}$ under the JCM; this represents a substantial savings, of US\$99.73 $\times 10^{6}$ compared with the TCM. Employment also benefited, increasing from $10071.23 \times 10^{4}$ people under the TCM to $10090.03 \times 10^{4}$ people under the JCM, for an increase of $18.80 \times 10^{4}$ people. It is worth noting that under the JCM, the optimal abatement quantities for Henan and Shaanxi provinces were higher than those under the TCM, but the abatement quantity decreased for Shanxi province. This may be because of the full consideration of the pollutant capacity, pollutant abatement ability, and employment under the JCM. Moreover, employment increased in Shanxi and Shaanxi provinces under the JCM compared with that under the TCM, whereas employment decreased in Henan province. This may be because the population of Henan province is so large. With the increasing intensity of pollution control, the negative spillover effect of industrial restructuring will promote the transfer of employees to the surrounding areas, but the total employment of the three regions nonetheless increased. In summary, the JCM for regional air pollution based on futures trading not only decreased the cost of pollution control, but also increased the overall regional employment.

\section{Conclusions}

Against the background of severe air pollution and rigorous government policies to mitigate the problem, it has become necessary to reduce pollutant control costs without adversely affecting employment. To accomplish these goals, we developed an emission rights futures trading model for joint air pollution control that accounts for employment, and then examined $\mathrm{SO}_{2}$ control in our study area in 2017 as a case study of the model. The results show that under the JCM, whether or not we accounted for employment affected both the cost of pollution control and employment. When we accounted for employment, the JCM both increased employment and reduced pollution control costs compared with the JCM results without accounting for employment. Furthermore, compared with the TCM, the JCM both increased employment and decreased the control cost. 
The JCM in the present study can help polluted regions balance environmental control with economic development to ensure that residents of the affected areas can earn a living whilst also having a healthier environment. The model also accounts for differences in the cost of pollution control among the cooperating regions, and uses futures-based trading methods to achieve a "win-win" effect, thereby increasing the ability to achieve sustainable development. Although we focused on pollution control within a single region of a country, it should be possible to extend the method to encourage countries to cooperate in regional air pollution control. The trading model for emission rights futures proposed in this paper can not only effectively stimulate cooperation among regions in pollution control and decrease pollution control costs, but also represents a financial instrument that can be traded in financial markets, thereby increasing the variety of financial instruments available, and improving the flexibility of financial markets to deal with risks. The United States and other developed countries have begun trading emissions future and options, and have achieved some success. For example, the Chicago's Climate Futures Exchange started the $\mathrm{SO}_{2}$ futures trading in 2003, and the European Climate Exchange began the emission rights futures and options trading for major atmospheric pollutants in 2005. However, because the financial markets of developing countries such as China are immature and the associated financial regulations are strict, these countries have not yet adopted emission rights futures and options trading. However, the emission rights futures trading model proposed in this paper is effective enough to encourage developing countries to test their ability to promote joint air pollution control. Furthermore, the JCM proposed in this paper can be used for additional pollutant control measures in other countries. This model has a high potential to improve air quality and fight climate change.

Author Contributions: Conceptualization, S.W. and L.Z.; Data curation, S.W. and L.Z.; Formal analysis, S.W., Y.Y., C.W., J.X. and D.L.; Funding acquisition, L.Z., J.X., X.B. and D.L.; Methodology, S.W.; Software, S.W.; Visualization, S.W.

Funding: This work was supported by grants from the National Social Science Foundation of China (Projects No. 16BGL146, 18AZD005), the National Natural Science Foundation of China (Projects No. 71874108), the Science and Technology Commission in Shanghai Municipality of China (Projects No. 17DZ1203101, 17DZ1203105), and the Natural Science Basic Research Plan in Shaanxi Province of China (Project No. 2018JM7005).

Conflicts of Interest: The authors declare no conflicts of interest.

\section{References}

1. Altieri, K.E.; Keen, S.L. Public health benefits of reducing exposure to ambient fine particulate matter in South Africa. Sci. Total Environ. 2019, 684, 610-620. [CrossRef]

2. Xie, Y.J.; Zhao, L.J.; Xue, J.; Hu, Q.M.; Xu, X.; Wang, H.B. A cooperative reduction model for regional air pollution control in China that considers adverse health effects and pollutant reduction costs. Sci. Total Environ. 2016, 573, 458-469. [CrossRef]

3. Ministry of Ecology and Environment of China. Available online: http://www.mee.gov.cn/xxgk2018/xxgk/ xxgk15/201901/t20190107_688741.html (accessed on 5 June 2019).

4. Ministry of Ecology and Environment of China. Available online: http://www.mee.gov.cn/xxgk/hjyw/201106/ t20110610_211888.shtml (accessed on 20 June 2019).

5. Zhang, H.L.; Sheng, D. Pollution prevention regulations and jobs: A pseudo-regression discontinuity model. J. Financ. Econ. 2019, 45, 58-74. (In Chinese)

6. Jia, S.W.; Yan, G.L.; Shen, A.Z. Traffic and emissions impact of the combination scenarios of air pollution charging fee and subsidy. J. Clean. Prod. 2018, 197, 678-689. [CrossRef]

7. Hu, X.R.; Sun, Y.N.; Liu, J.F.; Meng, J.; Wang, X.J.; Yang, H.Z.; Xu, J.Y.; Yi, K.; Xiang, S.L.; Li, Y.; et al. The impact of environmental protection tax on sectoral and spatial distribution of air pollution emissions in China. Environ. Res. Lett. 2019, 14, 054013. [CrossRef]

8. Dai, Y.; Li, N.; Gu, R.; Zhu, X.D. Can china's carbon emissions trading rights mechanism transform its manufacturing industry? Based on the perspective of enterprise behavior. Sustainability 2018, 10, 2421. [CrossRef] 
9. Stoerk, T.; Dudek, D.J.; Yang, J. China's national carbon emissions trading scheme: Lessons from the pilot emission trading schemes, academic literature, and known policy details. Clim. Policy 2019, 19, 472-486. [CrossRef]

10. Ge, S.X.; Yu, X.Y.; Zhou, D.Q.; Sang, X.Z. The integrated effect of carbon emissions trading and pollution rights trading for power enterprises a case study of Chongqing. Sustainability 2019, 11, 3099. [CrossRef]

11. Gigli, S.; Landi, D.; Germani, M. Cost-benefit analysis of a circular economy project: A study on a recycling system for end-of-life tyres. J. Clean. Prod. 2019, 229, 680-694. [CrossRef]

12. Landi, D.; Gigli, S.; Germani, M.; Marconi, M. Investigating the feasibility of a reuse scenario for textile fibres recovered from end-of-life tyres. Waste Manag. 2018, 75, 187-204. [CrossRef]

13. Shen, W.; Wang, Y. Adaptive policy innovations and the construction of emission trading schemes in China: Taking stock and looking forward. Environ. Innov. Soc. Trans. 2019, 30, 59-68. [CrossRef]

14. Wang, Q.; Gao, C.Y.; Dai, S.P. Effect of the emissions trading scheme on $\mathrm{CO}_{2}$ abatement in China. Sustainability 2019, 11, 1055. [CrossRef]

15. Dales, J.H. Pollution, Property and Prices: An Essay in Policy-Making and Economics; Edward Elgar Publishing: Cheltenham, UK, 1968.

16. Lin, B.A.; Jia, Z.J. Energy, economic and environmental impact of government fines in China's carbon trading scheme. Sci. Total Environ. 2019, 667, 658-670. [CrossRef] [PubMed]

17. Zhao, L.J.; Xue, J.; Gao, H.O.; Li, C.M.; Huang, R.B. A model for interprovincial air pollution control based on futures prices. J. Air Waste Manag. Assoc. 2014, 64, 552-560. [CrossRef] [PubMed]

18. Marina, E.; Andreas, P. EU Emissions Trading scheme in aviation: Policy analysis and suggestions. J. Clean. Prod. 2019, 237, 117734. [CrossRef]

19. Lee, C.Y.; Wang, K. Nash marginal abatement cost estimation of air pollutant emissions using the stochastic semi-nonparametric frontier. Eur. J. Oper. Res. 2018, 273, 390-400. [CrossRef]

20. Pisoni, E.; Volta, M. Modeling Pareto efficient PM10 control policies in Northern Italy to reduce health effects. Atmos. Environ. 2009, 43, 3243-3248. [CrossRef]

21. Rico-Ramirez, V.; Lopez-Villarreal, F.; Hernandez-Castro, S.; Diwekar, U.M. A mixed-integer programming model for pollution trading. Comput. Aided Chem. Eng. 2011, 29, 1256-1260. [CrossRef]

22. Cao, W.B.; Wang, H.; Ying, H.H. The effect of environmental regulation on employment in resource-based areas of China-An empirical research based on the mediating effect model. Int. J. Environ. Res. Public Health 2017, 14, 1598. [CrossRef]

23. Zhang, Z.Y.; Hao, Y.; Lu, Z.N. Does environmental pollution affect labor supply? An empirical analysis based on 112 cities in China. J. Clean. Prod. 2018, 190, 378-387. [CrossRef]

24. Sheriff, G.; Ferris, A.E.; Shadbegian, R.J. How did air quality standards affect employment at us power plants? The importance of timing, geography, and stringency. J. Assoc. Environ. Resour. Econ. 2019, 6, 111-149. [CrossRef] [PubMed]

25. Gray, W.B.; Shadbegian, R.J.; Wang, C.B.; Meral, M. Do EPA regulations affect labor demand? Evidence from the pulp and paper industry. J. Environ. Econ. Manag. 2014, 68, 188-202. [CrossRef]

26. Ash, M.; Boyce, J.K. Racial disparities in pollution exposure and employment at US industrial facilities. Proc. Natl. Acad. Sci. USA 2018, 115, 10636-10641. [CrossRef] [PubMed]

27. Wu, D.; Xu, Y.; Zhang, S. Will joint regional air pollution control be more cost-effective? An empirical study of China's Beijing-Tianjin-Hebei region. J. Environ. Manag. 2015, 149, 27-36. [CrossRef] [PubMed]

28. Zhou, Z.; Zhang, M.J.; Yu, X.H.; He, X.J.; Wang, K.; Shao, Q.; Wang, J.; Sun, H.X. PM 2.5 cooperative control with fuzzy cost and fuzzy coalitions. Int. J. Environ. Res. Public Health 2019, 16, 1271. [CrossRef]

29. Ding, Y.T.; Zhang, M.; Chen, S.; Wang, W.W.; Nie, R. The environmental Kuznets curve for PM 2.5 pollution in Beijing-Tianjin-Hebei region of China: A spatial panel data approach. J. Clean. Prod. 2019, 220, 984-994. [CrossRef]

30. Zhou, B.; Zhang, C.; Song, H.Y.; Wang, Q.W. How does emission trading reduce China's carbon intensity? An exploration using a decomposition and difference-in-differences approach. Sci. Total Environ. 2019, 676, 514-523. [CrossRef]

31. Zeeshan, K.; Zhu, S.S.; Yang, S.Q. Environmental regulations an option: Asymmetry effect of environmental regulations on carbon emissions using non-linear ARDL. Energy Sour. Part A-Recovery Util. Environ. Eff. 2018, 41, 137-155.

32. Bloznelis, D. Hedging salmon price risk. Aquacult. Econ. Manag. 2018, 22, 168-191. [CrossRef] 
33. Golub, A.; Lubowski, R.; Piris-Cabezas, P. Balancing Risks from Climate Policy Uncertainties: The Role of Options and Reduced Emissions from Deforestation and Forest Degradation. Ecol. Econ. 2017, 138, 90-98. [CrossRef]

34. Ankamah-Yeboah, I.; Nielsen, M.; Nielsen, R. Price formation of the salmon aquaculture futures market. Aquacult. Econ. Manag. 2017, 21, 376-399. [CrossRef]

35. Yang, C.; Poon, J.P.H. A regional analysis of China's green GDP. Eurasian Geogr. Econ. 2009, 50, 547-563. [CrossRef]

36. Xue, J.; Ji, X.Q.; Zhao, L.J.; Yang, Y.; Xie, Y.J.; Li, D.Q.; Wang, C.C.; Sun, W.J. Cooperative econometric model for regional air pollution control with the additional goal of promoting employment. J. Clean. Prod. 2019, 237, 117814. [CrossRef]

37. Shi, G.M.; Wang, J.N.; Fu, F.; Xue, W.B. A study on transboundary air pollution based on a game theory model: Cases of $\mathrm{SO}_{2}$ emission reductions in the cities of Changsha, Zhuzhou and Xiangtan in China. Atmos. Pollut. Res. 2017, 8, 244-252. [CrossRef]

38. Cornell, B.; French, K.R. Taxes and the Pricing of Stock Index Futures. J. Financ. 1983, 38, 675-694. [CrossRef]

39. Young, H.P.; Okada, N.; Hashimoto, T. Cost allocation in water resources development. Water Resour. Res. 1982, 18, 463-475. [CrossRef]

40. Wu, Y.H.; Xu, D.T. The n-person game models of allocation problems. J. Syst. Eng. 1990, 5, 14-22. (In Chinese)

41. Heaney, J.P.; Dickinson, R.E. Methods for apportioning the cost of a water resource project. Water Resour. Res. 1982, 18, 476-482. [CrossRef]

42. Yang, L.C.; Dong, X.L.; Xu, B. Spatial distribution and spillover effects of haze pollution in the Fen-Wei plain. J. Environ. Econ. 2018, 3, 75-87. (In Chinese)

43. National Bureau of Statistics of China. China Labor Statistical Yearbook, 2000-2017; China Statistics Press: Beijing, China, 2000-2017.

44. National Bureau of Statistics of China. China Statistical Yearbook on Science and Technology, 2000-2017; China Statistics Press: Beijing, China, 2000-2017.

45. National Bureau of Statistics of China. China Industry Economy Statistical Yearbook, 2000-2017; China Statistics Press: Beijing, China, 2000-2017.

46. National Bureau of Statistics of China. China Statistical Yearbook, 2000-2017; China Statistics Press: Beijing, China, 2000-2017.

47. National Bureau of Statistics of China. China Statistical Yearbook on Environment, 2000-2017; China Statistics Press: Beijing, China, 2000-2017.

48. Government of China. Available online: http://www.gov.cn/gongbao/content/2017/content_5163448.htm (accessed on 24 June 2019).

49. Xue, J.; Zhao, L.J.; Fan, L.Z.; Qian, Y. An interprovincial cooperative game model for air pollution control in China. J. Air Waste Manag. Assoc. 2015, 65, 818-827. [CrossRef]

50. Chen, P.; Hou, P.P.; Zhai, J.H.; Sun, W. A novel method for the comprehensive utilization of iron and titanium resources from a refractory ore. Sep. Purif. Technol. 2018, 226, 1-7. [CrossRef]

(C) 2019 by the authors. Licensee MDPI, Basel, Switzerland. This article is an open access article distributed under the terms and conditions of the Creative Commons Attribution (CC BY) license (http://creativecommons.org/licenses/by/4.0/). 